\title{
Risk factors for psychological stress among international business travellers
}

James Striker, Rose S Luippold, Lorraine Nagy, Bernhard Liese, Carol Bigelow, Kenneth A Mundt

\begin{abstract}
Objectives-This study investigated sources of self reported psychological stress among international business travellers at the World Bank, following up on a previous study showing that travellers submitted more insurance claims for psychological disorders. Hypotheses were that work, personal, family, and health concerns, as well as time zone travel, contribute to travel stress.
\end{abstract}

Methods-A travel survey was developed from focus groups and consisted of questions about these potential sources of travel stress. Surveys were sent to a random sample of staff, stratified by number of travel missions, age range, and sex. Canonical correlation analyses estimated the association between key survey items on sources of stress and two measures of travel stress.

Results-498 staff completed the survey. More than a third reported high to very high travel stress. Correlations between predictors and travel stress showed that social and emotional concerns (such as impact of travel on family and sense of isolation) contributed the most to such stress, followed by health concerns, and workload upon return from travel. Surprisingly, time zone travel did not contribute to the self reported stress of these travellers. There were few modifiers of stress, although respondents suggested that a day of rest after travel and reduced workloads would help.

Conclusions-The current study confirms clinical impressions about several correlates of travel stress. Similar research with travellers in other organisations could help to determine whether the findings from this study are valid and what measures can be taken to reduce the psychological health risks to travellers. (Occup Environ Med 1999;56:245-252)

Keywords: travel stress

As international business travel grows, increasing numbers of travellers will be exposed to health risks, including widely varying physical and psychological stressors. Because psychological health risks of travel for employees may have direct and indirect effects on work functioning, understanding the patterns of stress related to travel, and contributing factors may help businesses to plan workplace inter- ventions to maintain employee health and productivity.

This study is a follow up to our recently published epidemiological study of global business travellers at the World Bank, which suggested that travel related to work may contribute to psychological illness. ${ }^{1}$ Patterns of health insurance claims filed by employees who travelled regularly on international business trips were compared with patterns among employees who were non-travellers. The travellers were up to three times as likely as non-travellers to use health insurance for treatment of psychological disorders, and the number of business trips taken was positively related to use of these health services. Travellers also showed higher overall rates of medical claims. This study raised questions about the possible psychological health risks of travel, including the physical effects of travel across time zones (jet lag), varying health and safety concerns, personal and family disruptions, and excessive workload.

Others have described the health risks faced by travellers and the prevalence of illness related to travel, ${ }^{2-5}$ including the behaviours of travellers that are associated with increased risk of physical illness. ${ }^{6}$ Such studies have often focused on infectious diseases, especially gastrointestinal disorders and tropical diseases, or on injuries. Studies have also described how occupational factors can contribute to psychological distress, which may then increase the risks of both psychological and physical illness. ${ }^{7-9}$ Factors that have been identified as sources of stress include workload, job control, job satisfaction, relations with supervisors and work group, balance between work and family, and organisational change. ${ }^{9-12}$ Accumulation of work related psychological distress has been shown to be associated with physical illness, including a general perception of poor health, ${ }^{13}$ cardiovascular disease, ${ }^{914}$ and mental health problems. $^{9}{ }^{13}$ These potential health effects of work stress seem to occur across nationalities and cultures. ${ }^{15-17}$

Business travel is a unique challenge to the health of employees, which to date has not been studied extensively. One clinical study ${ }^{18}$ identified as stressors the pressures of planning the trip, time in the airport, disruption of circadian rhythms and sleep patterns, loneliness, and fear of dangerous ground transportation in destination countries. Limited research on psychological stress among travellers has documented personal and family stresses among oil workers, aircraft pilots, and their families, ${ }^{19} 20$ worries about health and safety related to 
travel, ${ }^{21}$ acute psychiatric illness among holiday travellers, ${ }^{22}$ and effects of jet lag on mood..$^{23}{ }^{24}$ To date, however, the relation between psychological stress and health risks for frequent business travellers is not well understood.

We report here on an exploratory study that builds upon our earlier findings, ${ }^{1}$ with the goal of investigating the sources of self reported psychological stress in the same population of more than 4500 international business travellers at the World Bank, in Washington, DC. Specifically investigated were the following three hypotheses: (a) severity of stress of travel related to work varies with work pressures, personal and family concerns, and health behaviours and attitudes; (b) stress of travel related to work varies with the number of time zones crossed and with amount of travel; (c) selected coping measures, including sources of support and work satisfaction, modify these relations.

\section{Methods}

The study consisted of preliminary pilot focus groups, to identify among travellers the key concerns that might lead to stress; development of a survey questionnaire; and the final survey of travellers. The study sample consisted of employees who submitted travel documentation for one or more international business trips during 1995.

PRELIMINARY FOCUS GROUPS AND DEVELOPMENT OF SURVEY METHOD

Computer assisted focus group meetings were held with small groups of volunteers, to identify themes for the main work, travel, health, and stress concerns of travellers. Themes that emerged were concerns about heavy workloads, family wellbeing, separation from family and friends, and health and safety risks while travelling. These were consistent with themes identified elsewhere. ${ }^{18}{ }^{21}$ Also, employees reported ways in which their work was satisfying as well as approaches for coping with the demands of their travel schedules.

The content of these sessions was used to construct the travel survey, and further input was obtained from the focus group participants and from staff in the organisation's medical department. Focus group participants were not eligible to participate in the main survey.

SUBJECT SAMPLE

A stratified random sample of 1293 potential participants was selected from a population of 4530 employees of the World Bank, who travelled at least once on international business during the 1995 calendar year. Potential participants included professional and managerial staff from more than 140 countries. They had a high level of education, many with doctoral degrees, as well as technical expertise in several areas related to world developmentagriculture, economics, education, energy, engineering, finance, health and social science, law, and other fields.

SAMPLING PLAN AND RECRUITMENT

In constructing our sample, we reasoned that stress associated with travel would vary by sex, age, and frequency of international travel. Therefore, a modified stratified random sampling plan was used to ensure adequate representation of distinct sex-age-frequency of travel profiles. Briefly, we identified 24 strata defined by sex (two groups), age (four groups), and frequency of travel (three groups). Within each stratum, except one, we identified for receipt of surveys a random sample of $25 \%$, with a minimum of 30 people. The exception, women aged $\geqslant 55$ with four or more missions numbered only 16 and all women in this stratum were selected. This produced a mailing list of 1293 employees. Travel surveys were distributed to all potential participants at their offices at headquarters. Incentives (randomly drawn lottery prizes) were offered for returning a completed survey, and anonymity of the respondents was guaranteed.

\section{MEASURES}

The survey questionnaire comprised 51 questions pertaining to demographics, work, and personal and health matters, with five point Likert scales, multiple choice questions, and open ended questions. There were two outcome variables, self reported overall stress of travel and health and psychological effects of stress related to travel, which were each measured on five point Likert scales. Three sets of primary predictors of stress were also queried on Likert scales: work pressures, rated on five items and considering sources of work pressure and control over travel schedule; personal and family concerns, assessed on six items about personal and family worries, contact with home when travelling, and sense of isolation; and health behaviours and attitudes, rated on nine items and pertaining to travel preparations, exercise, days off to rest, health and safety concerns, and concern about jet lag. Secondary predictors included travel across time zones to one of seven broadly defined regions of the world, plus frequency and duration of travel. Potential modifiers of stress included seven items on coping approaches and sources of work satisfaction. Hypothesised confounders measured included sex, age group, living alone, and presence of children under 18 years of age in the home.

\section{STATISTICAL ANALYSES}

Characteristics of the analysis sample were summarised with frequency distributions for sex, age group, living alone versus with others, presence or absence of children 18 years or younger at home, number of business trips, number of days of travel, and travel destination (region of the world).

Canonical correlation methods were used to investigate variations in the two stress outcomes-overall stress of travel and perceived effects of travel stress on health - relative to the three groups of hypothesised predictors: work pressures, personal and family concerns, and health behaviours and attitudes. The choice of canonical correlation to analyse the data was based on statistical ${ }^{25}$ and clinical reasons. 
Table 1 Characteristics and travel experiences of survey respondents $(n=498)$

\begin{tabular}{lrl}
\hline & $n^{*}$ & $\%$ \\
\hline Sex: & 155 & 31 \\
$\quad$ Female & 343 & 69 \\
$\quad$ Male & & \\
Age (y): & 80 & 16 \\
$\quad<35$ & 140 & 28 \\
$35-44$ & 172 & 35 \\
$45-54$ & 106 & 21 \\
$>54$ & & \\
Total days on mission (n): & 101 & 21 \\
$1-29$ & 120 & 25 \\
$30-59$ & 131 & 28 \\
$60-89$ & 125 & 26 \\
$\geqslant 90$ & & \\
Total missions (n): & 94 & 20 \\
$<2$ & 134 & 28 \\
$2-3$ & 130 & 27 \\
$4-5$ & 125 & 26 \\
$\geqslant 6$ & & \\
Distinct regions visited (n): & 306 & 63 \\
$<2$ & 104 & 22 \\
2 & 47 & 10 \\
3 & 26 & 5 \\
$4-6$ & & 4 \\
Traveled to western Europe only: & 20 & 96 \\
Yes & 463 & \\
No & & \\
\hline
\end{tabular}

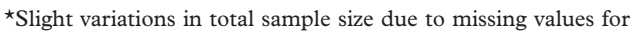
responses.

Canonical correlation analysis is appropriate for evaluating several possibly interrelated variables for the prediction of a multivariate outcome (in this study, the two measures of travel stress). Canonical correlations are correlations between linear combinations of the predictor and outcome variables. Their magnitudes are typically higher than correlations between pairs of individual variables because they exploit the greater strength of evidence of association that is inherent to multiple, interrelated, measurements. The technique is also appealing from a clinical perspective, in that it closely reflects the complexity of daily life experience. It allows for interpretation of results consistent with discussions in clinical practice of the interrelations among many variables.

Initial canonical correlation analyses considered each of the three groups of predictors separately. Results of these analyses identified the subsets of variables within each group that were significant correlates of stress. These analyses also guided the reduction of the initially large stock of potential predictors from 20 items to seven, with minimal loss of information. A second canonical correlation analysis on the reduced set of potential correlates investigated their joint relation to the two stress outcomes. A third set of canonical

Table 2 Distribution of self reported travel stress among survey respondents

\begin{tabular}{lrr}
\hline & $n$ & $\%$ \\
\hline Overall stress resulting from travel: & 35 & 7 \\
Very low & 74 & 15 \\
Low & 210 & 42 \\
Moderate & 138 & 28 \\
High & 37 & 8 \\
Very high & 127 & 26 \\
Travel stress affects physical and emotional health: & \\
Not at all & 151 & 31 \\
A little & 143 & 29 \\
Sometimes & 73 & 15 \\
Often or all the time & & \\
\hline
\end{tabular}

correlation analyses then investigated variations in these associations, after controlling for the hypothesised confounders and coping variables. Finally, as we were also interested in the roles of time zone travel and amount of travel on self reported stress, these were included in an additional canonical correlation analysis. Before analysis, the values for selected variables were collapsed to form grouped predictors, as their distributions in this sample were highly skewed.

Because the analysis plan resulted in the disproportionate sampling of selected subgroups, both weighted and unweighted analyses were performed. Results of the two approaches differed only negligibly. Therefore, only the unweighted results are presented. All analyses were performed with the SAS system. ${ }^{26}$

\section{Results}

Of the 1293 surveys sent to the randomly selected pool of potential participants, 498 (39\%) completed the travel survey. Because confidentiality was guaranteed by anonymity, only a limited characterisation of respondents and non-respondents was possible. An examination of response rates across sampling strata showed a great deal of variability. Although no clear patterns of response emerged, there was a tendency among both men and women for the response rate to increase with the number of missions, across all age groups (data available upon request). Additionally, participants were similar to the population of 4530 travellers in the organisation for age, sex, and number of business trips.

Over two thirds of the respondents were men and $56 \%$ were at least 45 years of age (table 1 ). Most $(63 \%)$ of the participants visited only one of seven world regions, although there was appreciable variation in the reported number of travel days and number of missions. Overall patterns of psychological distress are summarised in table 2 . Over one third $(36 \%)$ of the sample reported high to very high levels of travel stress, and only $7 \%$ indicated that mission travel was associated with very low levels of stress. Nearly half (44\%) reported that mission travel affected their physical and emotional health at least sometimes. Only $26 \%$ said there were no such effects. Not surprisingly, overall stress was strongly associated with self reported physical and emotional health effects of travel stress (Pearson's $r=0.68, \mathrm{p}=0.0001$ ).

BIVARIATE ASSOCIATIONS OF PREDICTORS WITH PSYCHOLOGICAL STRESS

Table 3 summarises the pairwise associations between stress of travel and the hypothesised predictors. Increased stress from travel accompanied increased work demand, some health concerns, and more personal and family concern. The strength of these trends was greatest for the grouping of variables about personal and family concerns, followed by variables on health and work pressure. Impact of travel on personal and family life, extent of isolation, preoccupation with family concerns, and opportunity to stay in touch had at least moderate positive associations with the stress 
Table 3 Pearson product moment correlations with travel stress among survey respondents

\begin{tabular}{|c|c|c|c|c|}
\hline \multirow[b]{3}{*}{ Association of travel stress } & \multicolumn{4}{|c|}{ Measure of stress } \\
\hline & \multicolumn{2}{|c|}{ Overall stress from travel } & \multicolumn{2}{|c|}{ Extent travel stress affects health } \\
\hline & $r$ & $p$ Value & $r$ & $p$ Value \\
\hline \multicolumn{5}{|l|}{ Work pressures $(n=479)$ : } \\
\hline More demanding workload on return & 0.33 & 0.0001 & 0.36 & 0.0001 \\
\hline Increased paperwork or administrative duties & 0.26 & 0.0001 & 0.28 & 0.0001 \\
\hline Less control over travel schedule & 0.20 & 0.0001 & 0.21 & 0.0001 \\
\hline Work weekends while on mission & 0.22 & 0.0001 & 0.17 & 0.0001 \\
\hline Decreased frequency of backup at headquarters & 0.13 & 0.006 & 0.15 & 0.001 \\
\hline \multicolumn{5}{|l|}{ Health behaviour and attitudes $(n=418)$ : } \\
\hline Greater concern about jet lag & 0.37 & 0.0001 & 0.42 & 0.0001 \\
\hline Worry about personal health and safety & 0.30 & 0.0001 & 0.38 & 0.0001 \\
\hline Attitude that day of rest is necessary ${ }^{\star}$ & 0.29 & 0.0001 & 0.26 & 0.0001 \\
\hline Exercise while on mission & 0.11 & 0.03 & 0.22 & 0.0001 \\
\hline Manager does not tend to grant recuperative day off & 0.07 & 0.15 & 0.12 & 0.02 \\
\hline Does not tend to obtain travel medication & -0.14 & 0.005 & -0.07 & 0.13 \\
\hline Does not tend to seek travel health information & -0.05 & 0.33 & -0.04 & 0.47 \\
\hline Does not tend to take rest day & -0.07 & 0.14 & -0.03 & 0.56 \\
\hline Exercise at headquarters & -0.07 & 0.13 & 0.01 & 0.81 \\
\hline \multicolumn{5}{|l|}{ Personal and family concerns $(n=472)$ : } \\
\hline Feeling more isolated from family or friends & 0.45 & 0.0001 & 0.41 & 0.0001 \\
\hline Preoccupation with personal or family concerns & 0.41 & 0.0001 & 0.39 & 0.0001 \\
\hline Negative impact of travel on family ${ }^{\star}$ & 0.36 & 0.0001 & 0.36 & 0.0001 \\
\hline Less opportunity to stay in touch & 0.30 & 0.0001 & 0.23 & 0.0001 \\
\hline Less able to rely on others back home & 0.18 & 0.0001 & 0.18 & 0.0001 \\
\hline Perception that family coped poorly & 0.13 & 0.006 & 0.14 & 0.002 \\
\hline
\end{tabular}

$\star$ Dichotomous coding.

measures ( $r=0.45$ to $0.23, \mathrm{p}=0.0001$ ). Workload on return from travel, the amount of paperwork and administrative demands, and extent of control over the travel schedule were also moderately correlated with travel stress. Among health behaviours and attitudes, jet lag concern, concern about health and safety, and attitude about a day of rest were correlated with stress of travel.

MULTIVARIATE ASSOCIATIONS WITH PSYCHOLOGICAL DISTRESS

The initial canonical correlation analyses of stress with each of the three sets of predictors separately identified several moderate associations and are described later (data not shown).
Among the predictors of work pressure, the highest canonical coefficient was obtained for greater workload on return from travel; moderate coefficients were obtained for less control over travel schedule and greater paperwork and administrative duties. Negligible coefficients were obtained for the measures of weekend work on a mission and backup at headquarters, suggesting that these variables are not important factors. The strength of the first canonical correlation with the variables on health behaviour and attitude was carried by the contribution of a variable indicating attitude about the need for a recuperative day of rest. Of moderate strength were the associations with stress of higher levels of worry about safety and

Table 4 Canonical correlation analyses of associations with stress of travel: predictors, confounders, and coping variables

\begin{tabular}{|c|c|c|c|}
\hline & Model 1 & Model 2 & Model 3 \\
\hline & $\begin{array}{l}\text { Canonical coefficient } \\
(n=475)\end{array}$ & $\begin{array}{l}\text { Canonical coefficient } \\
(n=473)\end{array}$ & $\begin{array}{l}\text { Canonical coefficient } \\
(n=437)\end{array}$ \\
\hline \multicolumn{4}{|l|}{ Outcomes: } \\
\hline Greater overall stress from travel & 0.49 & 0.48 & 0.48 \\
\hline Increased perception that travel stress affects health & 0.59 & 0.59 & 0.61 \\
\hline \multicolumn{4}{|l|}{ Hypothesised predictors: } \\
\hline Negative impact of travel on family or personal life & 0.50 & 0.52 & 0.48 \\
\hline Attitude that day of rest is necessary & 0.45 & 0.45 & 0.47 \\
\hline Greater concern about jet lag & 0.32 & 0.31 & 0.31 \\
\hline More demanding workload on return & 0.29 & 0.28 & 0.25 \\
\hline Feeling more isolated from family or friends & 0.28 & 0.28 & 0.32 \\
\hline Preoccupation with personal or family concerns & 0.27 & 0.30 & 0.30 \\
\hline Worry about personal health and safety & 0.18 & 0.18 & 0.16 \\
\hline \multicolumn{4}{|l|}{ Confounders: } \\
\hline Children under 18 in household & - & -0.14 & -0.17 \\
\hline Only adult in household & - & 0.10 & 0.10 \\
\hline Females & - & 0.04 & 0.05 \\
\hline Increased age & - & -0.04 & -0.05 \\
\hline \multicolumn{4}{|l|}{ Coping variables } \\
\hline Work satisfaction: work with team & - & - & 0.18 \\
\hline What helped cope: self support & - & - & -0.17 \\
\hline Main source of support: family or friends & - & - & -0.12 \\
\hline Work style in field: more autonomous & - & - & 0.06 \\
\hline Main source of support: own efforts & - & - & 0.06 \\
\hline Work satisfaction: escape demands of headquarters & - & - & 0.04 \\
\hline What helped cope with stress: phone calls home & - & - & -0.04 \\
\hline Canonical correlation $(\mathrm{p}=0.0001)$ & 0.69 & 0.69 & 0.70 \\
\hline Variance in stress explained (\%) & 40 & 40 & 41 \\
\hline
\end{tabular}

Model I=predictors are hypothesised predictors (work pressures, health behaviour, personal, and family concerns) only. Model II=predictors are hypothesised predictors from model I, plus confounders.

Model III=predictors are hypothesised predictors and confounders from model II, plus coping variables. 
Table 5 Canonical correlation analysis of associations with stress of travel to investigate role of travel predictors

Canonical coefficient $(n=442)$

\begin{tabular}{lc}
\hline Outcomes: & \\
Greater overall stress from travel & 0.48 \\
Increased perception that travel stress affects health & 0.60 \\
Work pressures: & \\
More demanding workload on return & 0.25 \\
Health behaviour and attitudes: & 0.39 \\
Attitude that day of rest is necessary & 0.31 \\
Greater concern about jet lag & 0.19 \\
Worry about personal health and safety & \\
Personal and family concerns: & 0.51 \\
Negative impact of travel on family or personal life & 0.33 \\
Preoccupation with personal or family concerns & 0.28 \\
Feeling more isolated from family or friends & \\
Travel predictors: & 0.26 \\
Primary destination: south Asia & 0.22 \\
Primary destination: Latin America or Carribean & 0.18 \\
Primary destination: sub-Saharan Africa & -0.15 \\
Greater number of total missions & 0.09 \\
Greater number of total travel days & -0.09 \\
Primary destination: western Europe & 0.03 \\
Primary destination: eastern Europe or central Asia & 0.01 \\
Greater number of distinct destinations & -0.004 \\
Primary destination: east Asia or Pacific & -0.11 \\
Primary destination: Middle East or north Africa & -0.21 \\
Confounders: & -0.04 \\
Children under 18 in household & 0.11 \\
Increased age & 0.02 \\
Only adult in household & 0.69 \\
Women & \\
Canonical correlation (p=0.0001) & \\
Variance in stress explained (\%) & \\
\hline & \\
\hline
\end{tabular}

concerns about jet lag. These associations were slightly stronger for the outcome of perceived health effects of travel stress. Negligible coefficients were obtained for the behaviours of seeking health information, getting regular exercise, and taking time off after travel. Among the variables on personal and family concerns, higher scores on both stress indicators were associated with relatively greater concerns about family, sense of isolation, and the impact of travel on personal and family life. Whether one could rely on others back home while travelling, having the opportunity to stay in touch with family and friends, and how well family coped while the employee was away contributed little to explaining travel stress. The reduced list of seven predictors was identified from these results.

Table 4 summarises the multivariate associations identified from three canonical correlation analyses of travel stress: the reduced set of seven predictors (model 1); these seven predictors plus the hypothesised confounders (model 2 ); and the seven predictors with confounders, plus the selected measures of coping (model 3 ). Overall patterns of association were stable across models. Increased travel stress was associated with perceived negative impact of travel on family and personal life, an attitude that a day of recuperative rest is necessary, greater jet lag concern, greater workload upon return, isolation from family and friends, preoccupation with personal and family concerns, and marginally with worry about personal health and safety. In model 2 , addition of the control variables of children under 18 years old in the household, other adults in household, sex, and age did not change the coefficients for the hypothesised predictors and none of the demographic variables contributed meaningfully to the model. A small attenuating effect on stress of having children under 18 in the household was found. Control for seven hypothesised coping variables in model 3 showed only two that were marginally predictive; increased stress from travel was marginally associated with satisfaction from teamwork, whereas decreased stress was marginally associated with relying on oneself to cope with stress.

Ten indices of destination (a proxy for time zones travelled) and amount of travel were added in a final canonical correlation analysis (table 5). Control for destination changed only negligibly the associations of the seven predictors shown in table 4 . There also continued to be a marginal, attenuating effect on stress of having children under 18 in the household. Increased stress of travel was marginally associated with destinations in south Asia and Latin America and the Carribean. There was no association of increased stress with number of days on a mission, but there was a trend toward reduced travel stress accompanying a greater number of distinct missions.

\section{Discussion}

WORK, HEALTH, AND SOCIAL CONCERNS

CONTRIBUTED TO DISTRESS

For this group of international travellers, the three groups of hypothesised primary predictors - work, health, and social-were all significantly associated with travel stress. Seven variables contributed to the relation between predictors and this distress, even after controlling for selected confounders and coping variables in canonical correlation analysis. However, travel stress was not related to age or sex. Three of the seven predictors were social concerns, with perceived negative impact of travel on family and personal life contributing the most. Also contributing were preoccupations with personal and family concerns and a sense of isolation from family and friends while on a mission. The one contributing work concern was the heavy workload that travellers faced upon return from a mission. Health concerns that contributed to travel stress included perception of jet lag and worries about personal health and safety. An attitude that a day of rest is necessary to recuperate from travel also seemed to contribute to higher stress levels among these travellers. Although most respondents think it is necessary, very few of them reported that they actually take rest days after business travel. Two thirds of all respondents reported that their managers rarely or never formally grant such days, yet almost $60 \%$ said management approved time off would help them cope better. The combination of this perceived lack of sanction for taking time off and the heavy workloads encountered after a travel mission may result in a repeated experience after a mission of high demand and low control-a situation identified by Karasek and Theorell ${ }^{11}$ and Bourbonnais et $a l^{10}$ as leading to psychological distress.

Stressed travellers were more concerned about symptoms of jet lag than those who were not stressed. Nevertheless, it is not clear whether jet lag was a specific stressor or that the highly stressed respondents were just more 
reactive to both the physical and psychological stresses of travel. The one survey question about jet lag was a measure of concern or distress over the symptoms, rather than an objective measure of those symptoms. Although jet lag has been described as an occupational stressor that results in fatigue and mood changes, ${ }^{23}$ the concern about jet lag reported in this sample seems to be a marker of stress, not a major stressor in itself.

The most important source of stress among these international travellers seems to be the effect of travel on their personal and family lives, accounted for by three of the seven predictors. The experiences of this group of travellers seems similar to that found in some studies of spouses of travelling workers. Feelings of isolation and mood changes have been described among the spouses of oil workers and airline crews, ${ }^{19}{ }^{20}$ and are said to result from difficult adjustments to repeated separations and reunions. A review of write in comments by respondents of the current survey (data not shown) reinforces the importance of these personal and family issues for all, not only for those who are the most highly stressed. Of comments from almost 350 respondents answering a question about the greatest pressures related to a travel mission, half were about the impact on family and personal life. Common themes included respondents' own feelings of separation and homesickness, and the difficult adjustments by themselves and their families to repeated separation and reunion. The worry of some travellers about risks to their own health and safety while traveling may even increase the feeling of isolation, as such potential threats to wellbeing occur far from home and family, and often in remote settings in developing countries.

PREDICTORS NOT RELATED TO TRAVEL STRESS

Several predictors did not correlate with travel stress in this survey. Among the work variables, non-significant predictors included degree of control over travel schedule, working at weekends, amount of paperwork and administrative demands, and amount of backup in the office while away. Perhaps even the highly stressed respondents considered these potentially high workload demands to be inevitable and manageable aspects of their work. Long hours of work, including weekends, were reported to be part of the work culture of these travellers while they were on a mission.

Among the social variables, the extent travellers could rely on others back home, how much opportunity there was to stay in touch with family and friends while on a mission, and perceptions of how family members coped in their absence were not associated with travel stress. This is surprising, especially as many of these travellers expressed concerns about the wellbeing of their families in written comments on the survey. It may be that the stresses related to these concerns were based more on their internal adjustments to repeated separations over time and the reported sense of isolation, which remain relatively unaffected by the presence or absence of these external circum- stances. Among the health variables, a more surprising result was the lack of association between travel stress and several preventive behaviours - such as regular exercise, seeking health information and travel medication, and regularly taking rest days after mission travel. Although engaging in these healthy behaviours can have positive effects on physical health, such behaviours did not contribute to the travel stress outcomes in this sample of travellers. This paradoxical result contradicts the frequent clinical recommendations given to travellers, especially regarding exercise and rest, to help reduce their stress. Such a result, however, may be specific to this particular sample of travellers.

TIME ZONE TRAVEL AND AMOUNT OF TRAVEL

An association between travel stress and travel destination was expected, as the destination is a proxy for the number of time zones crossed. Time zone travel, with the disruption of the circadian rhythm of the traveller, has been described as the key factor in jet lag, and it has been shown to be related to psychological and physical changes. ${ }^{22-24}$ Among the current sample of travellers, however, differences in stress by travel destination were inconsistent and apparently not related to travel across time zones. For example, respondents who travelled to east Asia were less likely to be stressed than those travelling to Latin America. This contradicted our assumption that the travellers to east Asia, crossing many times zones, would show higher stress levels because of the effects of jet lag. The results suggest that other factors-for example, organisational or destination specific, may better explain the higher stress among these travellers. Employees in the World Bank who travel to particular destinations are primarily from groups designated to work in those areas of the world. There are likely to be unmeasured group differences which may explain the different stress levels of these travellers. There may be variations in workload, approaches to how the work is managed, autonomy and control over work, or factors specific to travel destination. Lack of control and high work demands have been shown to contribute to psychological distress and depression, ${ }^{10}{ }^{11}$ and some supervisory approaches may contribute to episodes of stress related health problems. ${ }^{16}$ It may be that these psychosocial aspects of work, as well as the separations from home, have a greater impact than the physiological effects of time zone travel on the psychological and physical wellbeing of international travellers.

Although amount of travel was not a strong predictor of stress, the subgroup of those who travelled on the greatest number of missions was marginally less stressed. Although the effect was small, this result is inconsistent with the previous finding from the larger population of these same travellers ${ }^{1}$ that showed an increased rate of claims for psychological disorders among those who travelled more often. One explanation may be that there is not a clear association between the self reported travel stress as measured here and the occur- 
rence of psychological disorders. A high level of overall travel stress as measured by the travel survey used in this study may not be sensitive to the psychological stresses that require or result in people seeking counselling and psychotherapy. Because of the anonymity of the respondents, however, we cannot determine if this study sample included any of those who have sought psychological treatment or if the travel stress measured is the source of their seeking such health services. An alternative explanation could be that the current sample includes a selected subgroup of frequent travellers who have adapted well to travel, and who thus experience travel stresses to a lesser degree.

\section{COPING VARIABLES}

The marginal but attenuating effect on stress of self support suggests, as might be expected, that self sufficiency is important for coping among regular travellers. A surprising result was that satisfaction from work with a team seems to marginally add to the stress in this sample. This is particularly unexpected, given that team work could be hypothesised as providing social support and thus a buffer against stress. Karasek and Theorell ${ }^{11}$ have suggested that social support at work moderates the psychological effects of job strain, as indicated by a reduced occurrence of depression. Sixty per cent of the respondents to the current survey did say that they were more team oriented when on a mission, and $64 \%$ also derived satisfaction from close working relations with team members. They also reported, however, that they engaged in long hours of intense work while on a mission, including extended business meetings, which may have added to their physical and psychological stress rather than reducing it. Teamwork could thus be simultaneously a support and a stressor.

Given the reported experience of isolation among the stressed travellers, another unexpected result was the mildly attenuating effect on stress of having children in the household. One explanation may be that attachments to younger children help to emotionally sustain employees while they are travelling. A family unit with children may provide an important social support to reduce overall stress, despite the repeated separations of travel. It is also possible that these travellers have developed, out of necessity, a set of approaches to help them maintain good relations with their families and to lower stress levels.

Most of the travellers in this study indicated a preference for formally approved time off after business trips. Such time presumably would allow them to rest and recuperate, and to make a better transition back home. They chose this as something that would help them cope, even though those who actually took time off were no less stressed than their colleagues. This may reflect a desire by these business travellers for the organisation to formally acknowledge their personal needs especially as almost half of the respondents said that the institution should provide more support for maintaining balance between work and outside life. The work culture can make it difficult for employees to take advantage of time off, especially if workloads are consistently very heavy or if employees who take time off are perceived as being vulnerable or less committed. Caring, concern, and permission communicated by the organisation (managers) may better support stress management by employees, and put those who want to take a day off less in conflict with the expectations of their managers. Officially approved time off might also help relieve stress by giving travellers more of a sense of control, through providing another option, whether or not it is actually taken. Regarding the impact of overall demands of work, almost half of the respondents identified a need for more realistic workloads to help them cope with stress. Some workload demands can be self generated, especially in committed and intensely work focused employees. Workload levels are often externally imposed, however, and may depend on business needs, available resources, and how the work is managed. These workload issues can only be effectively considered through simultaneous review of both organisational and individual practices and priorities.

\section{STUDY LIMITATIONS}

The current study, like most surveys, is limited by its dependence on self reported measures, which are by nature subjective, ${ }^{27}{ }^{28}$ and rely on memory of previous events and emotional states. However, we have no reason to think that the survey responses were biased; respondents answered anonymously, and the questions were worded as objectively as possible with fixed coding. Indeed, anonymity was considered an important aspect of the study design and forced the use of a postal survey despite the lower response rates associated with this method. ${ }^{29}$

Our efforts to optimise the participation rate through the awarding of incentives and guaranteed anonymity yielded limited success; the overall response rate was 39\%, introducing a concern about selection bias. The tendency of higher response rates among more frequent travellers suggests that a selection bias may have been operating. However, the variability of response rates across sampling strata suggests that participation may also have been affected by timing and convenience. For example, we do not know the number of surveys sent to travellers who were essentially ineligible for the study because they were absent from headquarters at the time of the study due to travelling on a mission. Although respondents were similar to the overall travelling population of the organisation in terms of demographic characteristics, it is still possible that respondents were a subgroup whose selection is related to the variables studied. The prevalence of self reported risk factors and stress outcomes may not be representative of those in the larger target population.

Further potential bias in this sample of travellers may be related to personal characteristics that were not measured. The experience of dis- 
tress or willingness to report it could be related to personality traits, personal coping styles, or cultural background. We do not know if there were significant differences among respondents in these factors that may have affected our results.

We did not use validated measures of distress in the survey. However, our study examined correlates of the attribution of stress due to travel, an outcome for which we have found no validated measures. Although the symptoms of stress were not the focus of the study, adding a validated measure of physical and psychological symptoms of distress would have improved confidence about identification of distressed travellers.

Finally, the cross sectional study design does not allow definitive assessment of the temporal relation between travel distress and the identified correlates. For example, we cannot determine whether preoccupation with personal and family concerns was a consequence of the travel distress or, alternatively, existed before travel on a mission.

\section{CONCLUSIONS AND RECOMMENDATIONS}

International business travel is a stressful experience that will increasingly be studied in today's global business environment. The current study identified several correlates of travel stress, most notably the effects of travel on personal and family life, as well as heavy workload. Similar research with travellers in other organisations could help to determine whether the findings from this study are valid. These results may help to develop a better understanding of the potential effects of business travel on psychological health, as well as to guide organisations in taking pragmatic measures to reduce the risks of travel stress to their employees.

The most effective interventions to help reduce distress among travellers are likely to be those that include several levels in the organisation. Successful management of stress requires that education and other interventions be targeted at management, work groups, and individual employees, as there is shared responsibility for stress in any organisation - and there are shared benefits to maintaining health and wellbeing among employees. ${ }^{30}$ For the employees who travel regularly, health professionals in corporate medical departments can contribute training and guidance for good stress management and for maintaining a healthy life balance. These professionals can also facilitate the sharing of best practices that have been developed by many of their travelling colleagues for coping before, during, and after travel. Travel medicine in occupational settings should more regularly include attention to stress and psychosocial issues in consulting with business travellers.

1 Liese B, Mundt K, Dell L, et al. Medical insurance claims ssociated with international business travel. Occup Environ Med 1997;54:499-503.

2 Hill DR, Behrens RH. A survey of travel clinics throughout the world. Fournal of Travel Medicine 1996;3:46-51.

3 Gettleman MD. Emporiatrics: the study of diseases in travelers. Infect Control Hosp Epidemiol 1990;11:157-60.

4 Reid D, Cossar JH. Epidemiology of travel. Br Med Bull

5 Yung AP, Ruff TA. Travel medicine 2: upon return. Med F Aust 1994;160:206-12

6 Bryant HE, Csokonay WM, Love M, et al. Self-reported illness and sick behaviours amongst Canadian travelers while abroad. Can F Pub Health 1991;2:316-19.

7 Ganster DC, Schaubroeck J. Work stress and employee health. F Management 1991;17:235-71.

8 Holt RR. Occupational stress. In: Goldberger L, Breznitz S, eds. Handbook of stress, 2nd edition. New York: The Free Press; 1993:342-67.

9 Quick JC, Murphy LR, Hurrell JJ, eds. Stress and well-being at work. Washington, DC: American Psychological Association, 1992.

10 Bourbonnais R, Brisson C, Moisan J, et al. Job strain and psychological distress in white collar workers. Scand $\mathcal{F}$ Work Environ Health 1996;22:139-45.

11 Karasek R, Theorell T. Healthy work: stress, productivity, and the reconstruction of working life. New York: Basic Books, 1990.

12 Repetti RL. The effects of workload and the social environment at work on health. In: Goldberger L, Breznitz S, eds, Handbook of stress, 2nd edition. New York: The Free Handbook of stress,

13 Peterson M, Wilson J. Job satisfaction and perceptions of health. F Occup Environ Med 1996;38:891-8.

14 Bosma H, Marmot MG, Hemingway H, et al. Low job control and risk of coronary heart disease in Whitehall II (prospective cohort) study. BMF 1997;314:558-65

15 Lai G. Work and family roles and psychiatric well-being in urban China. f Health Soc Behav 1995;36:11-37.

16 Rubenowitz S. Can you get back pain because you have a rigid boss? Some empiric findings from the social service sector. Paper presented at the 25th International Conference on Occupational Safety and Health, Stockholm; September, 1996. (Unpublished)

17 Uehata T, Sekiya E, Sugisawa A, et al. A cohort study on the relationship between work stress and cardiovascular onset in fapanese male workers. Paper presented at the $25^{\text {th }}$ International Conference on Occupational Health, Stockholm; September, 1996. (Unpublished)

18 McIntosh IB. The stress of modern travel. Travel Medicine International 1990;8:118-21.

19 Morrice JKW, Taylor RC, Clark D, et al. Oil wives and intermittent husbands. Br F Psychiatry 1985;147:479-83.

20 Rigg RC, Cosgrove MP. Air crew wives and the intermittent husband syndrome. Aviat Space Environ Med 1994;5:65460

21 McIntosh IB, Power KG, Reed JM. Prevalence, intensity, and sex differences in travel related stressors. Fournal of Travel Medicine 1996;3:96-102.

22 Young DM. Psychiatric morbidity in travelers to Honolulu, Hawaii. Compr Psychiatry 1995;36:224-8.

23 Bassett J, Spillane R. Jet lag as an occupational stressor. fournal of Occupational Health and Safety-Australia and New Zealand 1985;1:26-32.

24 Naitoh P, Kelly TL, Englund C. Health effects of sleep deprivation. Occup Med 1990;5:209-37

25 Afifi AA, Clark V. Computer-aided multivariate analysis, $2 n d$ edition. New York: Van Nostrand Reinhold, 1990:252-69.

26 SAS Institute. SAS/STAT user's guide, version 6, fourth edition. Vols 1 and 2. Cary, NC: SAS Institute, 1989.

27 Derogatis LR, Coons HL. Self-report measures of stress. In: Goldberger L, Breznitz S, eds. Handbook of stress, 2nd edition. New York: The Free Press, 1993:200-33.

28 Cox T, Ferguson E. Measurement of the subjective work environment. Work Stress 1994;8:98-109.

29 Aday LA. Designing and conducting health surveys. San Francisco, CA: Jossey-Bass, 1989.

30 Quick JC, Quick JD, Nelson DL, et al. Preventive stress management in organizations. Washington, DC: American Psychological Association, 1997. 